DOI: $10.47456 / k r k r . v 1 i 4.31820$

\title{
Educação do campo: ocupar, resistir e produzir também na escola
}

\author{
Field education: occupy, resist and produce at school \\ Heloisa Vitória Castro Paula \\ Marcelo Cervo Chelotti
}

\begin{abstract}
Resumo: A Educação do Campo, com os princípios teóricos e pedagógicos que serão apresentados a partir da análise dos documentos do Setor de Educação e de produções acadêmicas do Movimento Por uma Educação do Campo, deve ser compreendida a partir do olhar do MST e da luta pela terra. Reconhecidamente foi dentro do movimento que se construíram os princípios que norteiam a Educação do Campo e a levam ao processo de institucionalização. Porém, não podemos negligenciar a pluralidade do campo material e teórico que se faz para além dos movimentos sociais, ao passo que reúne várias realidades e anseios diferentes. Diante do tamanho desse desafio, 0 objetivo desse texto é refletir sobre o caminho da educação pensada dentro dos movimentos sociais de luta pela terra, em consonância com os princípios que marcaram a trajetória da luta do movimento. Os caminhos trilhados desde 1992 ao ano de 2005, com os primeiros ensaios sobre Educação dentro do Setor de Educação do MST, refletindo sobre o legado da formação de professores dentro do movimento. As análises dos documentos do Setor de Educação do MST nortearam as reflexões deste trabalho. A pesquisa foi delineada por meio da pesquisa teórica e documental. As análises realizadas nos levam a reconhecer que foram rompidas as cercas da escola para se adentrar os muros das universidades. Não se fala somente em Educação para o Campo e sim em um projeto nacional de Educação do Campo, que vai da Educação Básica à Pós Graduação.
\end{abstract}

Palavras-Chave: Educação do Campo. Formação de Professores. Política Pública

Abstract: Field Education, with the theoretical and pedagogical principles that will be presented from the analysis of documents from the Education Sector and academic productions of the Movement for Field Education, must be understood from the perspective of the MST and the struggle for land. Admittedly, it was within the movement that the principles that guide Field Education and lead it to the institutionalization process were built. However, we cannot neglect the plurality of the material and theoretical field that goes beyond social movements, while it brings together several different realities and desires. Given the size of this challenge, the objective of this text is to reflect on the path of education within the social movements fighting for land, in line with the principles that marked the trajectory of the movement's struggle. The paths taken from 1992 to 2005, with the first essays on Education within the MST Education Sector, reflecting on the legacy of teacher training within the movement. The analysis of the documents of the MST Education Sector guided the reflections of this work. The research was designed through theoretical and documentary research. The analyzes carried out lead us to recognize that the school fences were broken in order to penetrate the university walls. There is talk not only of Education for the Countryside, but of a national project of Education of the Countryside, which goes from Basic Education to Postgraduate.

Keywords: Field Education. Teacher training. Public policy

\section{Introdução}


O Movimento dos Trabalhadores Rurais Sem Terra (MST) apresenta como marca de sua luta: Ocupar, Resistir e Produzir também na escola. Como preceito da educação idealizada pelo movimento, fala-se em uma educação construída por meio da cooperação, em que crianças, professores, lideranças, assentados e acampados comecem a discutir e a fazer uma escola diferente, que ajude nos enfrentamentos cotidianos (MST, 1992).

Depois de mais de duas décadas da publicação do primeiro boletim (19922019), a Educação do Campo reforça um projeto de educação que seja capaz de pensar uma escola que corresponda à realidade camponesa, que faça sentido para os seus alunos, que dê condições de reflexão sobre a vida no campo e que não dê como única alternativa aos filhos do campo irem para a cidade. Nesse sentido, o objetivo desse texto é refletir sobre o caminho da educação pensada dentro dos movimentos sociais de luta pela terra, partindo da experiência pioneira de Educação do Campo realizada dentro do MST, em consonância com os princípios que marcaram a trajetória da luta do movimento. O marco temporal pode ser situado entre os primeiros ensaios sobre Educação dentro do Setor de Educação do MST (1992) ao início da oferta dos cursos superiores de educadores do campo.

Miguel Arroyo (2014) aponta como os sujeitos da educação popular, ao tomarem consciência política, pressionam as concepções pedagógicas a repensarem-se nos processos de sua produção teórica, epistemológica. Para o autor,

As presenças dos Outros na agenda política e até pedagógica se tornam extremamente incômodas ao pensamento pedagógico porque os obrigam a se entender inseparável das formas políticas, culturais de produção/conformação com subalternos. Ao reagir a esses ser pensados e feitos subalternos desconstroem as autoidentidades do pensamento pedagógico. (ARROYO, 2014, p.11)

O reconhecimento da ruptura com a conformidade não pode estar fora da pauta de luta por Educação do Campo, cabe a esses sujeitos que buscam romper com o modelo de educação hegemônico assumirem o protagonismo dessa pedagogia, exigindo que sejam reconhecidos os princípios que os constituem. No Boletim da Educação dos 20 anos do MST, o movimento vê como 
tarefa principal a democratização da escola e das áreas de conhecimento. Reforçando que:

O MST aprendeu e deve compartilhar agora com os demais movimentos sociais, que sem conhecimentos científicos, sem acesso à educação, não vamos construir uma sociedade democrática, aonde todos tenham as mesmas oportunidades. Aprendeu de que os conhecimentos são mais importantes do que a terra. A terra é um bem da natureza, estático, que pode e deve ser democratizado. Mas o conhecimento não só liberta as pessoas, como transforma. E ajuda a transformar a própria terra (MST, Boletim da Educação do MST 20 anos, 2004, p. 70).

O compromisso que o Movimento assume com a educação faz rememorar a trajetória de luta e o faz reconhecer as suas origens, como herdeiro das lutas históricas de outros povos, por terra. É imprescindível, dentro dessa análise, apresentar a luta e a resistência do Movimento dentro da lógica de justiça social, que já não se enxerga sozinho nessa luta, trazendo para perto de seus ideais os pobres do campo e simpatizantes que tenham o mesmo sonho de construir uma sociedade justa para quem vive e sobrevive do campo.

Para avançar nesse objetivo, a luta pela educação caminhou junto à luta por terra, tendo a compreensão que mais que garantir o direito à terra, é preciso garantir a permanência nela. Foi preciso assumir um compromisso de ir ao encontro de uma educação pública, acessível e comprometida com os povos do campo.

\section{O princípio da luta por educação aliada a luta pela terra}

As primeiras experiências com crianças do Movimento começaram no início da década de 1980, ainda durante o período de constituição do MST. Em 1984 foi legalizada a primeira escola em assentamento. O surgimento das escolas nos assentamentos e acampamentos do MST era uma ação necessária para que o Estado fosse pressionado a atuar por meio de políticas públicas.

De acordo com o Balanço dos 20 anos do Movimento, no Boletim da Educação n. 09, primeiro se chegou à prática e, depois, ao conceito da Educação do Campo, "defendendo o direito que uma população tem de se educar e de pensar o mundo a partir do que faz e do lugar em que vive" (MST, BOLETIM n. 09, 2004, p.12). 
Neste contexto, foi importante vislumbrar que a luta não era somente de quem batalhava pela terra dentro de movimentos de luta pela terra, mas também de quem já vivia nela. Essa aliança seria capaz de fortalecer a luta por uma escola diferente, com uma concepção de educação e um método que se reconhecessem dentro da lógica dos povos do campo. Inseridas nos princípios da educação no MST nascem a Pedagogia do Movimento e a Educação do Campo. Tais construções convergem dentro da proposta da produção coletiva, enraizadas no diálogo teórico produzido dentro da perspectiva de classe e de ser humano.

A perspectiva é de que a Pedagogia do Movimento e a Educação do Campo sejam capazes de refletir sobre o conjunto de práticas que faz o dia a dia do homem/mulher do campo e a possibilidade de extrair delas o que é científico sem desvincular a escola da luta.

O desafio está em romper com a educação "bancária" e construir uma escola dialógica que, além do conhecimento científico, preocupe-se em agregar a formação humana ao indivíduo. Para tanto, a escola deve ser pensada em outra estrutura política e pedagógica. Para Caldart (2004, p. 3):

[...] a Educação do Campo faz o diálogo com a teoria pedagógica desde a realidade particular dos camponeses, mas preocupada com a educação do conjunto da população trabalhadora do campo e, mais amplamente, com a formação humana. E, sobretudo, trata de construir uma educação do povo do campo e não apenas com ele, nem muito menos para ele.

$\mathrm{Na}$ busca de se construir efetivamente uma escola capaz de dialogar com o cotidiano do campo, o Movimento investiu na formação dos professores que atuam nas escolas no campo, nos assentamentos e nos acampamentos. Desde 1990 vem realizando a formação de professores desenvolvendo cursos formais de formação de educadores do campo. Para situar esse percurso, é importante discorrer cronologicamente sobre essas iniciativas para que possamos visualizar as conquistas e os desafios enfrentados neste percurso.

\section{O caminho da formação de professores para a Educação do Campo}

Em 1990, o Movimento já iniciava a formação de professores em nível médio, em cursos de magistério, com o objetivo de formar professores para 
atuarem dentro dos assentamentos e acampamentos. A atuação com a formação de educadores do MST recebeu no ano de 1996 o prêmio da UNICEF, o que fortaleceu o engajamento dentro do setor de educação do movimento para o I Encontro de Educadores e Educadoras da Reforma agrária (ENERA), que aconteceu em 1997, tendo visibilidade interna e externa proporcionada pelo prêmio (MST, BOLETIM, n. 9, 2004).

Dentro deste mesmo movimento se iniciou a articulação para a Conferência Nacional "Por uma Educação Básica do Campo", que aconteceu em Luziânia (GO) de 27 a 31 de julho de 1998, "[...] precedida por Seminários estaduais, com o apoio em um texto-base e nas experiências concretas, ela constituiu um processo unindo muitos parceiros na sua animação." (ARROYO; FERNANDES, 1999, p. 8).

A Conferência foi capaz de agregar a Conferência Nacional dos Bispos do Brasil (CNBB), o Movimento dos trabalhadores rurais Sem Terra (MST), o Fundo das Nações Unidas para a Infância (UNICEF), a Organização das Nações Unidas para a Educação e Cultura (UNESCO) e a Universidade de Brasília (UNB).

Em relação às parcerias estabelecidas na construção do evento não podemos nos furtar à análise dos interesses que formaram esse grupo. Santos (2011) realiza uma análise das formulações e execuções de políticas encaminhadas a partir dos direcionamentos da Unesco e destaca que as metas apresentadas para a educação favorecem a trajetória acumulativa do mundo capitalista, sem risco de crises. A prioridade desse organismo e do Banco Mundial seria despolitizar a reforma agrária e sua atuação na educação do campo. O intuito é sustentar o problema da miséria, que é apresentada à parte da questão de classe, que para estes organismos está restrita à identidade e à cultura (LEHER, 2005).

Para Santos (2011, p. 155), "o afã de valorizar as culturas, os saberes, o cotidiano em nome de uma "nova" ciência que dê voz aos povos oprimidos, ofereceram uma teorização subjetivista e relativista da realidade." A perspectiva comunitarista influenciou os movimentos e tem naturalizado os acordos 
tripartites entre a burguesia, o Estado e a classe trabalhadora ou movimentos específicos (SANTOS, 2011).

No texto preparatório da Primeira Conferência Nacional "Por uma Educação Básica do Campo", escrito por Fernandes, Cerioli e Caldart (2004), os autores que fazem parte do Movimento Por uma Educação do Campo explicitam os enfrentamentos vivenciados pelo campo e que deveriam fazer parte do debate, considerando que:

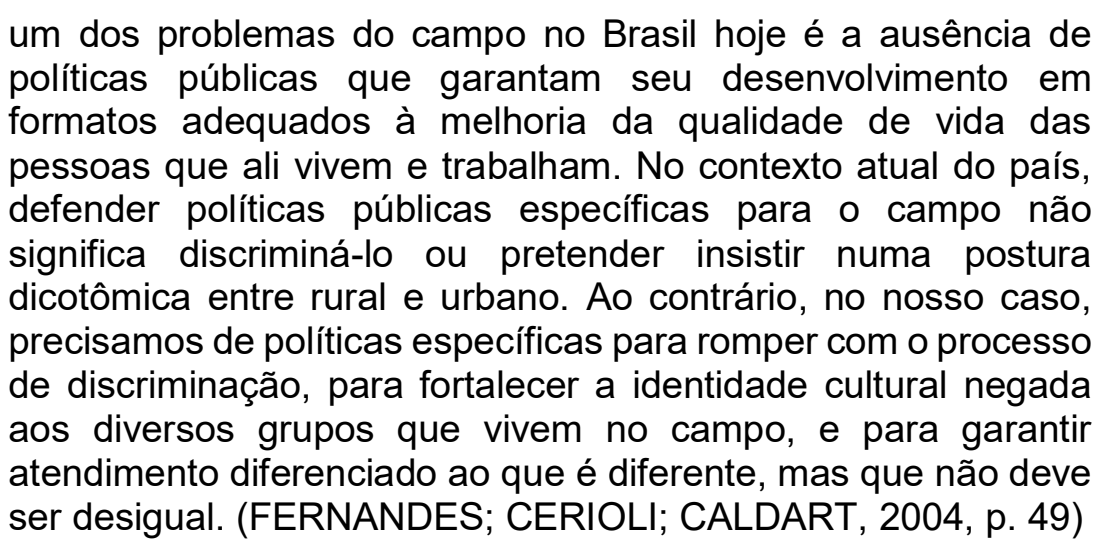

A partir do debate durante a Conferência, foi reforçada a importância de se discutir políticas públicas que atendessem à população do campo, sustentando as propostas de uma Educação Básica do Campo, condizente com a demanda do campo, implementando medidas que promovam o desenvolvimento social e garantam a valorização da população do campo. A Educação do Campo passa a ser vista com outro olhar, não mais como uma educação rural ou educação para o meio rural, mas agora com um projeto educativo legítimo, pensado para seus sujeitos.

Para Arroyo (2004), a educação básica tem que ser vinculada aos direitos, e é por isso que esta deve chegar até o trabalhador do campo. Para o autor, o "movimento social representa uma nova consciência do direito à terra, ao trabalho, à justiça, à igualdade, ao conhecimento, à cultura, à saúde e à educação" (ARROYO, 2004, p.72). Diante desta discussão se faz imprescindível pensar em uma prática pedagógica, em uma estrutura escolar e em uma escola que consiga promover este direito à educação básica (ARROYO, 2004).

O movimento Por uma Educação do Campo vê a escola como um importante instrumento na luta por uma Educação do Campo e, portanto, para 
que cumpra seu papel é importante que haja uma transformação no seu alicerce. Para Caldart (2010), a escola deveria trabalhar por um projeto histórico pelo qual os movimentos sociais lutam e, para isto, a escola deve ser "[...] transformada como escola pública, que no formato da sociedade capitalista atual acaba sendo privada." (CALDART, 2010, p. 19).

A importância da participação dos movimentos sociais na luta por uma Educação do campo tornou-se representativa pelo fato destes movimentos situarem a luta por educação no âmbito dos direitos, vinculando educação à saúde, à cooperação, à justiça e à cidadania (ARROYO, 2004).

Seguindo adiante no projeto do Setor de educação, que visava valorizar os educadores como os principais sujeitos do projeto pedagógico das escolas do campo, em 1998 surge a primeira experiência em nível superior com o curso da Pedagogia da Terra. As primeiras experiências dessa formação superior se deram em cursos para assentados da reforma agrária, e eram ofertados nas universidades parceiras dentro da perspectiva da pedagogia da alternância.

A primeira oferta do curso de Pedagogia da Terra foi no Rio Grande do Sul, com educandos assentados da reforma agrária de todo Brasil "[...] Essa bandeira também ganhou campo em outros estados, o que fez com que as turmas seguintes, a partir de 1999, tivessem um caráter regional, mas sempre envolvendo mais de um estado" (RIBEIRO, 2004, p. 50). Para o MST, a formação profissional de educadores se amplia para uma formação de militantes do setor e do Movimento, portanto, essa formação deveria se dar de forma diferenciada, sensibilizando e dialogando sobre as questões do campo, numa esfera social e política.

Quando o Movimento trata a formação numa perspectiva dialógica com a realidade do campo, ele quer trazer à tona as questões inerentes ao campo, como as questões agrárias e de desenvolvimento do campo. Esse olhar dialógico impulsionou a criação do Instituto de Educação Josué de Castro, que propunha uma educação específica e mantinha parcerias com as secretarias de educação e algumas universidades. Com a criação do Programa Nacional de Educação na Reforma Agrária, Incra/MDA (PRONERA) ainda no ano de 1998 o trabalho com os cursos formais foi impulsionado (MST, BOLETIM n. 09,2004). 
A criação de um programa com o olhar voltado para a luta por educação iniciada dentro do MST é reconhecidamente uma marco para a Educação do Campo, que, de acordo com o PRONERA, constrói-se na perspectiva de território, é um direito de todos e deve se realizar por diferentes territórios e práticas sociais que incorporam a diversidade do campo, garantindo e ampliando as possibilidades de criação e recriação de condições de existência e reexistência da agricultura familiar/camponesa. Para que isso se efetive, 0 PRONERA coloca como pano de fundo o fortalecimento do mundo rural em todas as suas dimensões: econômicas, sociais, ambientais, políticas e éticas.

Estava claro para o movimento que a discussão acerca da formação de educadores na perspectiva da Educação do Campo, como apresentado pelos movimentos sociais de luta pela terra, deveria permear as políticas públicas de educação para os povos do campo, explicitando o projeto de sociedade, de campo e de escola que se propõe construir.

O PRONERA estava vinculado ao Ministério do Desenvolvimento Agrário e veio ao encontro das discussões de uma política de formação de educadores do campo em nível superior, com formação política para os enfrentamentos da realidade do campo. De acordo com o Setor de educação do MST, "A experiência com as turmas de Pedagogia nos fez perder o medo da universidade e quebrou o mito de que camponês não pode ter espaço nela" (MST, BOLETIM n. $09,2004, p .17)$.

Apesar dos avanços no debate desde 1990, alguns pontos precisam avançar e outros retroceder, ao passo que, ao sair do campo e entrar nas universidades, a Educação do Campo por vezes vive um descompasso entre a formação pensada nas formações iniciais dentro dos assentamentos e acampamentos do MST e as propostas curriculares dos cursos de formação de professores. Para o MST,

[...] não podemos dizer que os cursos estejam preparando as pessoas que assumirão realmente a tarefa de mexer com a estrutura de nossas escolas públicas. Estamos ainda muito presos a um currículo tradicional de formação de educadores" (BOLETIM n. 9,2004, p. 17). 
O Setor de educação do MST reconhece que é preciso explicitar melhor as especificidades do papel do educador dentro do movimento para que se possa construir um projeto pedagógico adequado aos diferentes objetivos do Movimento.

Em 2010 foi aprovado o Decreto $n^{\circ}$ 7.352, que dispõe sobre a política de Educação do campo, e o Programa Nacional de Educação na Reforma Agrária (PRONERA). Ao analisar o Decreto $\mathrm{n}^{0} 7.352$ observamos que os princípios debatidos anteriormente vão ao encontro de uma perspectiva de educação do campo que surge como política educacional que dialoga com a realidade da população do campo, respeitando sua diversidade e particularidades. O Decreto, em seu Art. 1을 diz que (BRASIL, 2010, Art. 1으):

A política de educação do campo destina-se à ampliação e qualificação da oferta de educação básica e superior às populações do campo, e será desenvolvida pela União em regime de colaboração com os Estados, o Distrito Federal e os Municípios, de acordo com as diretrizes e metas estabelecidas no Plano Nacional de Educação e o disposto neste Decreto.

O entendimento do Decreto sobre quem faz parte dessa população do campo vai ao encontro das reflexões do MST ao refletir que não estavam sozinhos na luta por educação do campo, e que outros sujeitos também estavam excluídos da escola e que, para conseguir escolas, era preciso uma articulação maior com outras comunidades do campo, como forma de pressionar as secretarias de educação e o poder público a abrirem escolas no campo.

Podemos perceber, ao analisarmos o Decreto $n^{\circ} 7.352$, que os princípios ora estabelecidos vão ao encontro de uma perspectiva de Educação do campo, surgindo como política educacional que procura dialogar com a realidade da população do campo, respeitando sua diversidade e particularidades. O Decreto $\mathrm{n}^{\circ} 7.352$ norteia as proposições presentes em dois programas de governo construídos na perspectiva da Educação do campo e que buscam efetivar as políticas ora apresentadas para atenderem às demandas dos povos do campo.

Os programas aos quais o Decreto $n^{0} 7.352$ faz referência são o Programa Nacional de Educação na Reforma Agrária (PRONERA) e o Programa de Apoio à Formação Superior em Licenciatura em Educação do Campo (PROCAMPO). 
A discussão acerca da formação de educadores na perspectiva da Educação do Campo, como apresentado pelos movimentos sociais de luta pela terra e que deve permear estes programas, exige que seja explicitado o projeto de sociedade, de campo e de escola que se propõe construir. O Programa Nacional de Educação na Reforma Agrária estava vinculado ao Ministério do Desenvolvimento Agrário e surgiu em 1998, ano em que se iniciaram as discussões para uma política de formação de educadores do campo em nível superior.

O desafio agora se encontra no campo político da consolidação dos cursos, transcendendo o pensar epistemológica e empiricamente a formação dos educadores, mas também atender uma fragilidade na discussão das políticas públicas já diagnosticada dentro do movimento, que, apesar de intuitivamente ser direcionado desde sua essência à luta pela relação do direito social e à noção de público, ainda acredita que essa discussão deva ser fortalecida entre os professores para que haja um debate mais político e ideológico da educação do campo entre as diferentes organizações camponesas. (MST, BOLETIM n.09,2004).

Os cursos de Licenciatura em Educação do Campo surgem como uma possibilidade de ir ao encontro de compreender a educação a partir da escola, refletindo sobre a relação teoria e prática. Dos professores formados dentro dos cursos aparentemente se espera que sejam capazes de fazer da escola um lugar de produção de conhecimento, valorização do trabalho do homem/mulher do campo, promoção da emancipação desses sujeitos, ao passo que permite reinventar práticas pedagógicas e educativas.

Dentro da perspectiva da Pedagogia do Movimento de que a educação deve considerar o modo de vida, a cultura e a organização social dos sujeitos do campo, a formação em Regime de Alternância foi o caminho escolhido para a condução de muitas iniciativas educacionais do movimento sem-terra, como ocorreu com a Pedagogia da Terra. O movimento sem-terra chegou a ter convênios com mais de 50 universidades públicas e comunitárias com cursos funcionando no Regime de Alternância. Os períodos de estudos com tempos diferenciados de aprendizagem permitiam que "os assentados pudessem 
estudar sem sair do campo ou sair do campo para estudar. (RIBEIRO, 2010, p. 190)."

A mesma metodologia inspirou posteriormente a orientação dos cursos de Licenciatura em Educação do Campo. No edital No 02/2012 a Alternância aparece como um dos critérios para que o projeto submetido ao edital pudesse ser avaliado:

c) apresentar organização curricular por etapas equivalentes a semestres regulares cumpridas em Regime de Alternância entre Tempo-Escola e Tempo-Comunidade. Entende-se por TempoEscola os períodos intensivos de formação presencial no campus universitário e, por TempoComunidade, os períodos intensivos de formação presencial nas comunidades camponesas, com a realização de práticas pedagógicas orientadas;

A escolha por organizar os cursos superiores para os sujeitos do campo em Regime de Alternância parte da compreensão de que a interação entre o tempo e o espaço tornaria a formação integrativa e poderia manter o vínculo dos estudantes do campo com suas comunidades ao mesmo tempo em que estivessem vinculados à universidade. Dessa forma, seria possível manter o aspecto educativo dos dois tempos (Tempo Universidade e Tempo Comunidade).

Mesmo com a proposta integrativa da metodologia, a escolha pelo Regime de Alternância de certa forma se configurou como um desafio aos cursos de Licenciatura em Educação do Campo selecionados no edital 02/2012. Apesar dos projetos apresentarem uma proposta de Alternância, essa metodologia ainda era desconhecida em muitas universidades e o incentivo financeiro oferecido a cada IFES no valor de $\mathrm{R} \$ 4.000,00$ por estudante, pagos em uma única parcela anual, era somente de custeio $^{1}$, o que fez com que, diante da realidade estrutural de muitos campi das universidades selecionadas, o valor fosse insuficiente para estruturar os cursos e manter adequadamente a alternância (BRASIL, 2012).

\footnotetext{
${ }^{1}$ Recursos de custeio (correntes) são aqueles aplicados nas despesas com contratos de prestação de serviços, aquisição de materiais de consumo, diárias, passagens, bolsas e benefícios aos estudantes.
} 
A organização dos cursos, através do Regime de Alternância, impactou a dinâmica tradicional das universidades, demandando uma nova organização do espaço-tempo que desse conta da dinamicidade dessa formação.

Os impactos se dão pela própria ocupação dos espaços da universidade e no acolhimento aos alunos, que demandam alojamentos e refeitórios que deem conta de acolher os alunos durante o Tempo Universidade. Em contrapartida dos tempos, quando a universidade vai até as comunidades rurais acompanhar o Tempo Comunidade, depende de transporte e diárias para deslocar os professores e/ou tutores. Todo esse movimento dos tempos demanda um montante importante de recursos financeiros o que, por vezes, dificulta o andamento adequado dos cursos.

A educação em Regime de Alternância se tornará um importante instrumento metodológico não somente para a Educação Básica, como afirma o Parecer 01/2006, mas será um instrumento fundamental para a garantia do ensino superior a esses sujeitos, tendo em vista que os seus elementos fundantes estão pautados na promoção de mudanças que vão além do espaço tempo e não podem ser reduzidas a simples relações de teoria-prática.

Nesse contexto, alguns programas importantes vão subsidiar 0 desenvolvimento da educação dos povos do campo, dentre eles, o PRONERA e o PROCAMPO.

\section{O PRONERA e O PROCAMPO}

A partir da visão de luta e resistência, que é parte constituinte da Educação do Campo, surge o Programa Nacional de Educação na Reforma Agrária (PRONERA), que, posteriormente, desencadeou a criação do Programa de Apoio à Formação Superior em Licenciatura em Educação do Campo (PROCAMPO).

O PRONERA surge como um projeto educacional que visava promover a educação desses sujeitos protagonistas das lutas por terra no Brasil, sendo gestado durante o Encontro Nacional de Educadores e Educadoras da Reforma Agrária (ENERA), no ano de 1997. 
Naquele ano (1997) se comemorava os dez anos do Setor de Educação do MST e era necessário avaliar o caminho percorrido. Antecedendo o encontro, o MST publica o Manifesto das Educadoras e Educadores da Reforma Agrária ao povo brasileiro, criticando o projeto neoliberal que avançava sobre a nação e conclamando a participação da classe trabalhadora brasileira para se posicionar.

Em trechos do manifesto, o Movimento ressalta o que os leva a lutar por educação, considerando que a Educação: "é um elemento fundamental nos processos de transformação social" (MANIFESTO, 1997). Os anseios descritos no Manifesto falam de uma escola que garanta o "direito de pensar e de participar das decisões sobre a política educacional" e que tenha uma "identidade própria do meio rural, com um projeto-pedagógico que fortaleça novas formas de desenvolvimento para o campo".

O grito dos educadores e educadoras da reforma agrária por valorização profissional e por condições dignas de trabalho e de formação ecoou durante o ENERA. Foi possível perceber que havia mais forças dispostas a agregar essa luta por educação básica e ensino superior para o campo iniciada pelo movimento, criando-se uma articulação entre os diversos sujeitos e instituições envolvidas (MANIFESTO, 1997).

O maior desafio estava em avançar na escolarização dentro dos assentamentos que registravam, a partir de números do I Censo Nacional da Reforma Agrária, números extremamente baixos, que chegavam a $43 \%$ de analfabetos nas áreas do assentamento. Diante de um número tão baixo de escolaridade o primeiro passo foi atender à demanda da alfabetização de jovens e adultos.

A partir da elaboração de um projeto educacional que começou a ser gestado dentro do ENERA, foi construído e apresentado um documento no III Fórum do Conselho de Reitores das Universidades Brasileiras, nos dias 6 e 7 de novembro de 1997. Em 16 de abril de 1998, por meio da Portaria No. 10/98, o Ministério Extraordinário de Política Fundiária criou o PRONERA (RIBEIRO, 2010).

A proposta do PRONERA aponta a Educação do Campo como direito de todos, devendo se realizar por diferentes territórios e práticas sociais que 
incorporam a diversidade do campo, garantindo e ampliando as possibilidades de criação e recriação de condições de resistência da agricultura familiar/camponesa. Para que isso se efetive, o PRONERA se propõe a fortalecer o mundo rural em todas as suas dimensões: econômicas, sociais, ambientais, políticas e éticas. De acordo com Ribeiro (2010),

O objetivo do Pronera (sic) é promover o acesso à educação formal em todos os níveis aos trabalhadores e trabalhadoras nas áreas da reforma agrária. [...] Em convênio com mais de 50 universidades públicas e comunitárias, os cursos garantem a chamada alternância regular de períodos de estudos com tempos diferenciados de aprendizados, de maneira que os assentados possam estudar sem sair do campo ou sair do campo para estudar (RIBEIRO, 2010, p. 190).

É importante reconhecer o PRONERA como instrumento fundamental de acesso à educação formal dos povos do campo. Inspirado pelo movimento de educação já existente dentro dos movimentos de luta pela terra, o programa escolarizou um número relevante de jovens e adultos da reforma agrária, transcendendo esse universo para a universidade. De acordo com a II PNERA,

no período de 1998 a 2011, foram realizados 320 cursos do Pronera por meio de 82 instituições de ensino em todo o país, sendo 167 de EJA fundamental, 99 de nível médio e 54 de nível superior. [...] Os 320 cursos foram realizados em 880 municípios, em todas as unidades da federação. Muitos desses cursos foram realizados concomitantemente, com uma média nacional de mais de cinco ocorrências por curso, abrangendo 1.753 realizações. (PNERA, 2015, p.22)

No que tange à primeira demanda registrada na implementação do PRONERA referente à alfabetização de adultos, de 1998-2011 foram realizadas 101.245 matrículas de alunos nas turmas de Educação de Jovens e Adultos (EJA) coordenadas pelo programa. Desde sua criação, o PRONERA vem realizando projetos de Educação de Jovens e Adultos, cursos profissionalizantes e de nível superior. Vale destacar que os cursos acontecem dentro do regime de alternância, como forma de garantir diferentes tempos e espaços educativos, que possibilitem a permanência desses sujeitos sociais nos cursos.

Em diálogo com o movimento que vem se construindo nas duas últimas décadas do século XXI, os movimentos sociais e sindicais do campo de luta pela terra, por meio de encontros, conferências, debates, fóruns, marchas e cursos 
de capacitação, constroem processos permanentes de educação popular, trazendo para a sociedade civil a discussão sobre "Cidadania" e "Educação" do homem do campo, passando pelas dimensões presentes no PRONERA. Para Arroyo (1999, p. 9),

[...] os movimentos sociais são em si mesmos educativos em seu modo de se expressar, pois o fazem mais do que por palavras, utilizando gestos, mobilizações, realizando ações, a partir das causas sociais geradoras de processos participativos e mobilizadores.

Em 2012, foi lançado o Programa Nacional de Educação do Campo (PRONACAMPO). De acordo com o Ministério da Educação e Cultura, o subprograma se propõe às seguintes ações, distribuídas em eixos (MEC):

I Eixo: Gestão e Práticas Pedagógicas

Programa Nacional do Livro Didático - PNLD Campo

Programa Nacional Biblioteca da Escola — PNBE Temático

Mais Educação Campo

II Eixo: Formação Inicial e Continuada de Professores

Formação Inicial e Continuada de Professores

Escola da Terra

III Eixo: Educação de Jovens e Adultos e Educação Profissional

EJA Saberes da Terra

Programa Nacional de Acesso ao Ensino Técnico e Emprego

IV Eixo: Infraestrutura Física e Tecnológica

Construção de Escolas

Inclusão Digital

PDDE Campo - Programa Dinheiro Direto na Escola

PDDE Água e Esgoto Sanitário - Programa Dinheiro Direto na Escola

Luz para Todos na Escola

Transporte Escolar

Dentro do Eixo II: Formação Inicial e Continuada de Professores se encontra o PROCAMPO, que se destina à formação de professores nos cursos de Licenciatura em Educação do Campo, em regime de alternância, e que é parte importante das análises propostas por essa pesquisa. Ainda em 2012 foi 
lançado um edital para selecionar 42 novos cursos de Licenciatura em Educação do Campo, a serem ofertados nas Universidades Federais e Institutos Federais e Educação, Ciência e Tecnologia, com habilitação para a docência multidisciplinar em várias áreas do conhecimento, sendo elas: linguagens e códigos, ciências humanas, ciências da natureza, matemática e ciências agrárias. A oferta desses cursos foi ao encontro dos anseios dos movimentos sociais que lutam pela garantia de direitos dos povos do campo e quilombolas.

A atuação do PRONERA e do PROCAMPO nas áreas da Reforma Agrária e no campo, ao proporem "ampliar o nível de escolarização formal dos trabalhadores rurais", abriram caminho para que se efetivasse uma política educacional para o campo que desencadearia uma legislação que atenderia às particularidades desses povos, incluindo indígenas e quilombolas que, de certa forma, foram fortalecidos pelo movimento por Educação do Campo, que alcançou debates em torno da diversidade.

O reflexo da atuação desses programas pode ser visualizado de forma quantitativa nas comunidades rurais. Por meio do levantamento dos dados sobre o impacto do PRONERA no campo, já é possível observarmos o aumento da escolaridade desses sujeitos. É importante ressaltar que os resultados positivos do PRONERA impactam a efetivação orgânica do PROCAMPO. Ao passo que a população do campo avança na escolaridade da Educação Básica, já é possível vislumbrar o ingresso no ensino superior.

De acordo com o DataPronera, que é o banco de dados do Programa Nacional de Educação na Reforma Agrária, somente nos primeiros 13 anos (1998-2011) o programa alcançou mais de 164 mil assentados, contabilizando da alfabetização de adultos ao nível superior nos cursos de graduação. Estimase que durante esse período foram "realizados 320 cursos de Educação de Jovens e Adultos (EJA) fundamental e de ensinos médio e superior. Os cursos envolveram 82 instituições de ensino, 38 organizações demandantes e 244 parceiros." (PNERA, 2015).

Já foram realizadas três pesquisas sobre o desempenho do PRONERA. A primeira avaliação foi realizada por meio de estudos de casos dentro das modalidades de ensino atendidas pelo PRONERA. A segunda pesquisa, 
intitulada I Pesquisa Nacional sobre Educação e Reforma Agrária (PNERA), foi desenvolvida entre novembro de 2004 e fevereiro de 2005 e "realizou 24.500 entrevistas em 1.651 municípios de todo o Brasil, visitando 5.595 assentamentos." (PNERA, 2015)

A I PNERA foi responsável pela inserção das escolas do campo no censo do Instituto Nacional de Estudos e Pesquisas Educacionais Anísio Teixeira (INEP) a partir de 2005. A II PNERA, que teve seus resultados publicados em 2015, buscou construir o DataPronera como um banco de dados permanente e atualizável com os dados das ações do Pronera. Esses dados dão subsídio para se propor políticas de educação do campo e acompanhamento das escolas no campo.

Os cursos do PRONERA foram realizados em todas as unidades da federação, sendo 320 cursos, oferecidos em 880 municípios. Esse movimento de educação dos sujeitos da Reforma Agrária já pode ser percebido dentro dos levantamentos estatísticos dessas regiões no que tange à alfabetização, considerando que a maior parte dos cursos compreendeu a alfabetização $(28,4 \%)$ e os anos iniciais do ensino fundamental $(14,4 \%)$.

Entre 1998 e 2011, é possível verificar que o número de turmas de alfabetização de jovens e adultos representou mais da metade do número de educandos matriculados nos cursos do PRONERA, representando $61,4 \%$ do número de educandos (II PNERA, 2015, p.32).

Esse número reflete o levantamento realizado na I PNERA, em 2004, que registrava que todas as regiões apresentavam uma porcentagem superior a $50 \%$ dos assentados que declaravam não frequentar a escola, sendo que mais de $20 \%$ diziam nunca terem frequentado a escola e não sabiam ler e nem escrever. (I PNERA, 2004)

No levantamento realizado em 2004, o número de famílias que tinham membros frequentando algum curso em nível superior era ainda menor, refletindo a falta de oportunidades para os povos do campo. A proporção geral alcançou somente $1,3 \%$ dos participantes da pesquisa.

Para Arroyo (2010), a relação entre educação e desigualdades tem sido um campo de estudo fecundo que leva à reflexão sobre a análise e a avaliação 
de políticas educativas. O autor aponta que mesmo que os estudos e pesquisas venham se desenvolvendo no meio acadêmico, muitas vezes não são considerados na formulação e gestão das políticas públicas, que, por vezes, privilegiam "resultados mensuráveis de avaliações oficiais generalistas, parciais, impressionistas" (ARROYO, 2010, p. 3).

As desigualdades educacionais, para Arroyo (2010), continuam persistentes e incômodas apesar dos avanços na compreensão dos complexos processos de produção-reprodução das desigualdades. Ao passo que se ignoram análises importantes que consideram fatores determinantes para a reprodução dessas desigualdades, apontando o papel histórico do próprio sistema e o "peso determinante das desigualdades sociais, regionais, raciais, sobre as desigualdades escolares na formulação de políticas, na sua gestão e avaliação" (ARROYO, 2010, p. 4), ignoram-se as relações educação-sociedade. Para o autor, é preocupante que as relações educação-políticas-desigualdades fiquem secundarizadas nas análises educacionais.

Os resultados apresentados pela PNERA I e II refletem o papel das políticas públicas educacionais para os sujeitos da Reforma Agrária e dos movimentos sociais na conquista dessas políticas voltadas aos sujeitos do campo. O protagonismo dos movimentos sociais e sindicais foi de suma importância para a garantia de participação na elaboração de políticas públicas para o campo.

O Movimento da Educação do Campo esteve presente na elaboração de importantes ações voltadas aos povos do campo, como PRONERA, Residência Agrária, Saberes da Terra, PROCAMPO (MOLINA; ANTUNES-ROCHA, 2014). A participação desses movimentos em instâncias executivas pôde resguardar 0 que as autoras Molina e Antunes-Rocha (2014, p. 226) chamam de um "projeto de escola que se articula com os projetos sociais e econômicos do campo, a partir da perspectiva de um projeto popular de desenvolvimento, e que cria e estabelece uma conexão direta entre formação e produção".

Os movimentos sociais estiveram presentes na Comissão Nacional de Educação do Campo (CONEC), vinculada à Secretaria de Educação Continuada, Alfabetização, Diversidade e Inclusão (SECADI) do Ministério da 
Educação, sendo representantes e interlocutores desses movimentos e sindicatos com o Estado.

O I Censo Nacional da Reforma Agrária (1996) apontava o baixo nível de escolaridade nos assentamentos. De acordo com o Atlas que apresenta a Situação Social e Demográfica dos Beneficiários da Reforma Agrária, publicado em 1998 a partir dos dados do censo e com o apoio do Instituto de Pesquisa Econômica Aplicada (IPEA), "O nível de formação dos beneficiários é, globalmente, muito ruim: cerca de $30 \%$ deles são analfabetos." (DAVID; WANIEZ; BRUSTLEIN, 1998, p. 22). A análise da realidade desses sujeitos cobrava urgência nas ações para que se pudesse reverter essa realidade.

Outro dado importante apresentado pelo Censo em 1996 são as diferenças regionais marcantes no Sul e na frente pioneira do Oeste, que puderam direcionar as prioridades. De acordo com os dados apresentados:

[...] Existem duas populações diferentes de beneficiários do ponto de vista do nível de formação: os nordestinos e os outros. Pode-se verificar que, no Ceará, mais de $60 \%$ dos beneficiários são analfabetos. Mesmo sem atingir esse extremo, o resto do Nordeste permanece em uma situação deplorável: a taxa de analfabetos entre os beneficiários não se situa, a não ser excepcionalmente, abaixo de $30 \%$. (DAVID; WANIEZ; BRUSTLEIN, 1998, p. 22)

A participação de sujeitos da Reforma Agrária nos debates e na articulação sobre a educação como direito de todo cidadão pôde colocar essa realidade estatística em pauta. Para tanto, a primeira ação a ser investida foi de alfabetização e formação de educadores dentro dos assentamentos (MOLINA; ANTUNES-ROCHA, 2014). Gradativamente, foi possível ofertar outros níveis dentro da Educação Básica para se chegar aos cursos profissionalizantes e superiores para os trabalhadores assentados.

O PRONERA se estabeleceu como um espaço importante de acumulação de vivências e experiências educativas, que foi essencial para que esse projeto de Educação do Campo fosse para além dos assentamentos. As diferentes licenciaturas ofertadas pelo PRONERA fortaleceram o debate teórico prático envolto na formação de educadores do campo, impulsionando a criação da Licenciatura em Educação do Campo por meio do PROCAMPO. 
Através dos dados da II PNERA, é possível verificar que entre os anos de 1998 e 2011, foram oferecidos através do PRONERA, 42 cursos de ensino superior, 6 cursos de especialização e 6 cursos de residência agrária. Nos dados apresentados nas duas pesquisas (PNERA) ainda não é possível analisar os reflexos no nível de formação dos sujeitos com a criação dos cursos de Licenciatura em Educação do Campo oferecidos a partir de 2007 por meio dos editais do PROCAMPO.

É possível vislumbrar que esse número relativo ao acesso desses sujeitos ao ensino superior tenha se ampliado nos últimos anos devido ao alcance desses cursos.

\section{A Educação do Campo e a Formação de Professores}

Após mais de uma década do início da experiência da oferta das Licenciaturas em Educação do Campo, podemos considerar que o projeto de educação que está à frente pauta-se em uma matriz formativa que valoriza a formação humana em todos os seus aspectos (sociais, intelectuais, emocionais, físicos) e se propõe a romper com as estruturas historicamente oferecidas aos povos do campo.

A expansão da oferta de cursos de Formação de Professores para atuarem nas escolas do campo é a materialização da luta dos movimentos de luta pela terra. Pensar um projeto que atenda à realidade do campo busca desmistificar o homem/mulher do campo dos rótulos impostos ao longo da história. Aliado a esse caminho se encontra a educação e uma formação de professores voltada ao reconhecimento da luta do campo e dos anseios em construir um projeto político pedagógico capaz de sistematizar todos esses saberes. Essa construção pautada na Pedagogia do Movimento inevitavelmente passará pelo viés da luta de classes e das relações de trabalho no campo.

A Educação do Campo vê a formação de professores como um instrumento capaz de fazer repensar a escola do campo. Ao repensar a escola do campo é preciso compreender a complexidade desse campo, que, não por acaso, fez com que se ampliasse o diálogo para além dos movimentos semterra, tendo em vista a diversidade de sujeitos que vivem no campo. Aquele que 
desconhece o campo, por vezes, render-se-á a uma visão personificada de um campo como lugar de atraso e esvaziado de cultura e educação ou visto por um olhar bucólico e romantizado, um lugar de descanso.

O professor que atua no campo deve ser capaz de reconhecer as possíveis contradições, mas também de agir a partir delas, o quer irá exigir desse profissional uma capacidade pedagógica para que não se perca no senso comum e no relativismo.

O MST, à medida que se empenha na formação de professores para atuarem nas escolas dos assentamentos e acampamentos, tinha claro que a educação era um instrumento essencial para garantir a convicção dos sem-terra sobre a luta. A atuação de um professor do movimento seria uma forma de estabelecer esse diálogo com a luta e garantir que as crianças tivessem acesso à escola, era uma forma de agregar mais famílias à luta.

Podemos dizer que o projeto de educação do MST foi audacioso, ao passo que se empenhava na formação de professores para atuarem no campo, partindo da perspectiva da luta pela terra. Dessa feita, esperava-se não somente que o professor fosse capaz de atuar sobre a realidade do campo a partir de suas habilidades pedagógicas, mas também de atuar "[...] para além da docência no intuito de ser agente da realização do direito humano à educação e do desenvolvimento social sustentável" (SANTOS, 2013, p. 211).

Nas primeiras experiências docentes nos acampamentos do MST, as crianças acampadas eram ensinadas de forma intuitiva pelas mães ou outros adultos, que voluntariamente ensinavam as crianças nas tendas, para que elas não perdessem o ritmo escolar. Por onde fossem os sem-terra, a escola fazia parte da estrutura da luta, nascia, portanto, a Escola Itinerante. Posteriormente, esse modelo de educação foi reconhecido pelas Secretarias de Educação. De acordo com o Boletim 20 anos (2004, p. 38),

A escola itinerante traz um método que desde os primeiros momentos de discussão pela Reforma Agrária se construiu para incluir as crianças do campo na escola. Seu projeto educacional foi baseado nos princípios de uma educação libertadora, inspirada em Paulo Freire, que valoriza o ser humano e a realidade por ele vivida. 
A escola itinerante surge como possibilidade de se manter na escola os sujeitos da luta, constituindo-se como espaço de afirmação das identidades dos sujeitos do campo. O Setor de Educação do MST nasceu da necessidade de educar as crianças acampadas e, neste contexto, nasce a preocupação de se formar e capacitar os professores, de se alfabetizar os jovens e adultos e de se pensar métodos de ensino que fossem ao encontro dos anseios do movimento (MST, BOLETIM 20 ANOS, 2004).

Sendo a formação de professores uma preocupação e uma necessidade do MST, inicia-se, no ano de 1990, no Rio Grande do Sul, o primeiro curso de magistério do MST, com o apoio da Fundação de Desenvolvimento à Pesquisa (FUNDEP). As turmas aconteciam dentro do âmbito do estado, em 1994, chegam à região centro-sul e, em 1997, passam a atender à primeira turma nacional.

Neste movimento de formação de professores, no ano de 1998 se iniciou a primeira turma do curso de Pedagogia, também no Rio Grande do Sul, e em 1999 se expandiu para outras regiões, sempre articulando mais de um estado. O Instituto de Educação Josué de Castro (IEJC), que tem como mantenedora o Instituto Técnico de Capacitação e Pesquisa da Reforma Agrária (Iterra), surgiu em diálogo com essa frente de educação dentro do MST, visando a formação técnica e profissional, a formação de militantes e de professores, partindo da demanda que era apresentada dentro dos setores do Movimento. Desde 2001, o IEJC oferta o curso normal de Nível Médio, nova designação do curso de Magistério.

Para Stédile (2012), três fontes levam o movimento a se preocupar com Educação. A primeira é a necessidade de ter entre os seus militantes pessoas com formação técnica para lidar com a terra, a segunda é formar frentes com conhecimento humano e a terceira fonte é a inspiração ideológica de que o MST deve lutar contra três cercas: a do latifúndio, a do capital e a da ignorância. (STÉDILE; FERNANDES, 2012)

Para se romper com as cercas apresentadas por Stédile (2012), a formação do professor dentro das premissas do Movimento é, antes de tudo, política e ideológica. Para que o professor seja capaz de relacionar teoria e 
prática, com vistas a uma formação transformadora, é preciso que se reconheça como sujeito dessa luta por uma educação libertadora.

A Educação que se faz mediadora da hegemonia em curso, como afirma Lefebvre (apud CURY, 1985, p. 14), "não pode e não pôde consumar-se sem certo consentimento pelo menos passivo da classe operária". Por vezes, a escola é usada como espaço mediador dessa hegemonia que "enquanto ideologia dominante tenta garantir, mediante um discurso homogêneo, a divisão social e suas consequências (CURY, 1985, p.47)". Para o autor, a função educativa fazse meio de implantação e consolidação da ideologia, tentando tornar coesa a classe que a gera (CURY, 1985).

É nesse movimento que se inicia a luta por Educação do Campo nas últimas décadas do século $X X$, adentrando o século $X X I$, visando alcançar o direito à educação e a outros direitos fundamentais da sociedade contemporânea, haja vista que se negligenciou sistematicamente a população do campo no que tange à garantia desses direitos.

\section{Conclusão}

Para que fosse possível estabelecer um diálogo entre o projeto de educação do MST e a formação de educadores do campo, a consulta aos boletins e cadernos temáticos publicados na página oficial do Movimento foi imprescindível para identificar os princípios pedagógicos fundamentais para se pensar a escola do movimento e os princípios norteadores para a Educação do Campo.

Ao realizar a análise documental foi possível compreender que a escola deve ser aliada desses sujeitos sociais na luta e resistência por permanecer no campo e viver da terra, com o fruto do seu trabalho. Não obstante, fala-se da escola do trabalho como uma forma de levar a criança, desde os anos iniciais, a se relacionar com o trabalho e se apropriar do produto do seu trabalho.

A Educação do Campo pensada pelos movimentos sociais de luta pela terra, se propõe a pensar o indivíduo em suas múltiplas dimensões. A formação humana dos sujeitos se alia à matriz formativa (o trabalho; a luta social; a organização coletiva; a cultura e a história), com o intuito de se pensar o 
indivíduo como um todo. As complexidades humanas se entrelaçam, ao passo que a formação humana considera o ser humano em seus aspectos: físico, biológico, psíquico, cultural, social e histórico.

Podemos dizer que é desses preceitos que a Educação do Campo não pode se afastar se quer se fazer instrumento de resistência e emancipação dos povos do campo. Para tanto, o desafio está em pensar na formação de professores, educadores do campo, vislumbrando o que o MST se propôs desde as primeiras iniciativas do Setor de Educação e vem reafirmando em sua trajetória, que é construir "uma concepção de educação, um método de fazer a formação das pessoas, uma concepção de escola" (MST, BOLETIM N. 09, 2004, p.14).

A formação humana centrada na coletividade e na luta está presente nas propostas de Educação do Campo, que acredita que esse é o caminho para se formar sujeitos com transformação social, focados na luta permanente por dignidade e justiça. Espera-se portanto que os cursos de formação de professores sejam capazes de sustentar em suas matrizes curriculares e práticas, os anseios de luta por uma identidade própria das escolas do campo, que sejam capazes de construir coletivamente um projeto político e pedagógico que vise o fortalecimento do campo, valorizando a cultura camponesa e os princípios que construíram a Educação do Campo.

\section{Referências}

ANTUNES-ROCHA, M. I.; DINIZ, L. de S.; OLIVEIRA, A. e M. Percurso formativo da Turma Dom José Mauro: segunda turma do curso de Licenciatura Plena em Educação do Campo da FAE-UFMG. In: MOLINA, M. C.; SÁ, L. M. (Orgs.) Licenciaturas em educação do campo: registros e reflexões a partir das experiências piloto (UFMG; UnB; UFBA e UFS). Belo Horizonte: Autêntica, 2011.

ARROYO, Miguel G. Educação básica e movimentos sociais. In: ARROYO, Miguel G.; FERNANDES, Bernardo M. (Orgs.) A educação básica e o movimento social do campo. Brasília: Articulação Nacional por uma Educação Básica do Campo, 1999.

ARROYO, Miguel G. Outros sujeitos, outras pedagogias. 2. ed. Petrópolis, RJ: Vozes, 2014.

ARROYO, Miguel G.; CALDART, Roseli S.; MOLINA, Mônica C. (Org.). Por uma educação do campo. Petrópolis: Vozes, 2004. 
BRASIL, Ministério do Desenvolvimento Agrário, Instituto Nacional da Colonização e Reforma Agrária (Incra), I Censo da Reforma Agrária do Brasil, 1996/1997, microdados.

BRASIL. Decreto $\mathrm{n}^{\circ} \mathbf{7 . 3 5 2}$, de 4 de novembro de 2010. Dispõe sobre a política de educação do campo e o Programa Nacional de Educação na Reforma Agrária - PRONERA. Brasília, 2010.

BRASIL. II PNERA: Relatório da Segunda Pesquisa Nacional sobre a Educação na Reforma Agrária. Brasília/DF: Ipea, 2015. Disponível em: http://www.incra.gov.br/pt/agroecologia/2-uncategorised/229-ii-pesquisanacional-de-educacao-na-reforma-agraria-pnera-jun-2015.html Acesso em: nov. 2019

BRASIL. Ministério da Educação. Edital N. X/2012. Edital de seleção SESU/SETEC/SECADI/MEC.

BRASIL. Ministério da Educação. Instituto Nacional de Estudos e Pesquisas Educacionais Anísio Teixeira. Ministério do Desenvolvimento Agrário. Instituto Nacional de Colonização e Reforma Agrária. Programa Nacional de Educação na Reforma Agrária. Pesquisa Nacional da Educação na Reforma Agrária (versão preliminar). Brasília, DF: 2005. Disponível em: portal. $\mathbf{m e c}$. gov. .br/index. php?catid=201\&id=2408\&option. Acesso em: 10 nov. 2019

BRASIL. Parecer $n^{\circ} \mathbf{3 6 / 2 0 0 1}$. Dispõe sobre as Diretrizes Operacionais para a educação básica nas escolas do campo. Brasília, 2001.

BRASILIA (DF). Secretaria de Educação Continuada, Alfabetização e Diversidade. Educação do campo: diferenças mudando paradigmas. Cadernos SECAD 2. Brasília (DF), 2007. 81p.

CALDART, Roseli. Licenciatura em Educação do Campo e projeto formativo: qual o lugar da docência por área? In: CALDART, R. S. (Org). Caminhos para a transformação da escola: reflexões desde práticas da Licenciatura em Educação do Campo. São Paulo: Expressão Popular, 2010.

CALDART, Roseli. Por uma Educação do Campo: traços de uma identidade em construção. In: ARROYO, Miguel G.; CALDART, Roseli S.; MOLINA, Mônica C. (Org). Por uma Educação do Campo. Petrópolis: Vozes, 2004. p. 147-160.

CONFERÊNCIA NACIONAL DE EDUCAÇÃO DO CAMPO (CNEC): Por uma Política Pública de Educação do Campo. 2., 2004. Luziânia-GO. Texto Base... Luziânia-GO, 2-6 ago. 2004.

CONSELHO NACIONAL DE EDUCAÇÃo (CNE). Conselho Pleno. Parecer 009/2001 de 08 de maio de 2001. Dispõe sobre as Diretrizes Nacionais para a Formação de Professores da Educação Básica, em nível superior, curso de licenciatura, de graduação plena. Brasília, 2001. 
CURY, Carlos Roberto Jamil. Elementos metodológicos para uma teoria crítica do fenômeno educativo. São Paulo: Cortez: Autores Associados, 1985.

DAVID, Maria Beatriz de Albuquerque et al. Situação social e demográfica dos beneficiários da reforma agrária: um atlas. Rio de Janeiro, IPEA, Texto para Discussão n. 548, março de 1998.

FERNANDES, B. M.; CERIOLI, PL. R.; CALDART, R. S. Primeira conferência nacional "Por uma Educação Básica do Campo". In: ARROYO, M. G.; CALDART, R. S.; MOLINA, M. C. (Orgs.). Por Uma educação do campo. Petrópolis, RJ: Vozes, 2004.

II CONFERÊNCIA NACIONAL POR UMA EDUCAÇÃO DO CAMPO. Declaração final (versão preliminar). Luziânia, 2004. Disponível em: www.slideshare.net/Escolas/declaracioniiconferenciaeducacaocampo Acesso em: março 2018

LEHER, R. Wolfowitz no Banco Mundial: educação como segurança, 2005. Disponível em: $\quad$ http://www.adur-ri.org.br/5com/popup/Banc Mund educ como seguranca.htm. Acesso em: Agosto/2019.

Molina, M. C., \& Antunes -Rocha, M. I. Educação do Campo, História, Práticas e Desafios no Âmbito das Políticas de Formação de Educadores: Reflexões sobre o Pronera e o Procampo. Revista Reflexão e Ação, 22 (2). (2014)

MST. MOVIMENTO DOS TRABALHADORES RURAIS SEM TERRA. Boletim da Educação n.1. Ocupar, produzir e resistir. 1. ed. Setor de Educação do MST, 1992.

MST. MOVIMENTO DOS TRABALHADORES RURAIS SEM TERRA. Boletim da Educação n.2. Como trabalhar a mística do MST com as crianças. 1. ed. Setor de Educação do MST, 1993.

MST. MOVIMENTO DOS TRABALHADORES RURAIS SEM TERRA. Boletim da Educação n. 3. Como trabalhar a comunicação nos assentamentos e acampamentos do MST. 1. ed. Setor de Educação do MST, 1993.

MST. MOVIMENTO DOS TRABALHADORES RURAIS SEM TERRA. Boletim da Educação n. 4. Escola, trabalho e cooperação. 1. ed. Setor de Educação do MST, 1994.

MST. MOVIMENTO DOS TRABALHADORES RURAIS SEM TERRA. Boletim da Educação n. 9. Educação no MST, balanço 20 anos. 1. ed. Setor de Educação do MST, 2004.

PAULA, Heloisa Vitória de Castro. Territórios e projetos em disputa na institucionalização dos cursos de licenciatura em educação do campo. 2020. 226f. Tese (Doutorado em Geografia) - Universidade Federal em Uberlândia, Uberlândia, 2020. 
RIBEIRO, Marlene. Movimento camponês, trabalho e educação. São Paulo: Expressão Popular, 2010.

RIBEIRO, Marlene. Reforma agrária, trabalho agrícola e educação rural: desvelando conexões históricas da educação do campo. Educ. Pesqui., São Paulo, v. 41, n. 1, p. 79-100, jan./mar. 2015. https://doi.org/10.1590/s1517$\underline{97022014111587}$

SANTOS, C. E. F. Relativismo e Escolanovismo na formação do educador: uma análise Histórico-Crítica da Licenciatura em Educação do Campo. 2011. 270 f. Tese (Doutorado em Educação) - Universidade Federal da Bahia, Salvador, 2011.

STÉDILE, J. P; FERNANDES, B. M. Brava Gente: a trajetória do MST e a luta pela terra no Brasil. 2. ed. São Paulo, 2012.

\section{Sobre os Autores}

\section{Heloisa Vitória Castro Paula}

heloisavcp@hotmail.com

Professora Adjunta da Universidade Federal de Goiás (UFCAT em implantação). Formada em Pedagogia pela Universidade Federal de Goiás. Especialista em Neuropedagogia e Psicanálise. Mestre em Geografia pela Universidade Federal de Goiás e Doutora em Geografia pela Universidade Federal de Uberlândia. Atua no Ensino Superior no curso de Licenciatura em Educação do Campo da Universidade Federal de Goiás (UFCAT em implantação). Coordena o estágio obrigatório do curso de Licenciatura em Educação do Campo. Coordenou o curso de Licenciatura em Educação do Campo da UFG (UFCAT em implantação) entre 2014-2016. Coordenou a tutoria do curso de especialização Ensino Interdisciplinar sobre infância e direitos humanos pela UFG (2016), subsidiado pela Capes. Pesquisa principalmente os seguintes temas: Educação do campo e Formação de Professores.

\section{Marcelo Cervo Chelotti}

mcervochelotti@gmail.com

Professor Associado, docente nos cursos de Graduação (Bacharelado e Licenciatura) e Pós-Graduação (Mestrado e Doutorado) em Geografia da Universidade Federal de Uberlândia (MG). Pós-Doutorado pela UFRGS. Doutorado em Geografia pela Universidade Federal de Uberlândia (UFU-MG), com estágio na Universidade de Buenos Aires (UBA). Mestrado em Geografia pela Universidade Estadual Paulista (UNESP-PP). Graduação em Geografia pela Universidade Federal de Santa Maria (UFSM-RS). Coordenador do Curso de Graduação em Geografia UFU (2013-2017). Coordenador de área do PIBID Interdisciplinar (2014-2018). Membro do Laboratório de Geografia Agrária (LAGEA) e Núcleo de Estudos Agrários e Territoriais (NEAT-CNPq). Experiência 
em Geografia Humana, com ênfase em Geografia Agrária, atuando principalmente nos seguintes temas: Ruralidades contemporâneas; Reprodução social da agricultura familiar, Expressões da alimentação e cultura no território; e Políticas públicas da educação do/no campo. 